\title{
Reducing the Toxicity of Designer Aminoglycosides as Nonsense Mutation Readthrough Agents for Therapeutic Targets
}

\author{
Michael Popadynec, Alireza Baradaran-Heravi, Benjamin Alford, Scott A. Cameron, Keith Clinch, \\ Jennifer M. Mason, Phillip M. Rendle, Olga V. Zubkova, Zhonghong Gan, Hui Liu, Oscar Rebollo, \\ Dennis M. Whitfield, Fengyang Yan, Michel Roberge,* and David A. Powell*
}

Cite This: ACS Med. Chem. Lett. 2021, 12, 1486-1492

Read Online

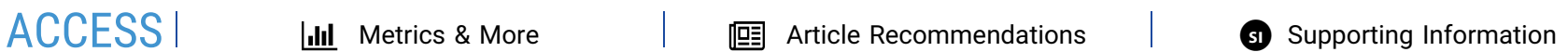

ABSTRACT: A significant proportion of genetic disease cases arise from truncation of proteins caused by premature termination codons. In eukaryotic cells some aminoglycosides cause readthrough of premature termination codons during protein translation. Inducing readthrough of these codons can potentially be of therapeutic value in the treatment of numerous genetic diseases. A significant drawback to the repeated use of aminoglycosides as treatments is the lack of balance between their readthrough efficacy and toxicity. The synthesis and biological testing of designer aminoglycoside compounds is documented herein.

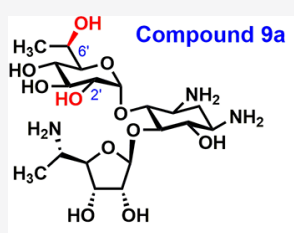

Premature termination codon readthrough agents with reduced overall cationic charge and toxicity

We disclose the implementation of a strategy to reduce cellular toxicity and maintain readthrough activity of a library of compounds by modification of the overall cationic charge of the aminoglycoside scaffold through ring I modifications.

KEYWORDS: Designer aminoglycosides, nonsense mutations, genetic diseases, premature termination codon readthrough

$\mathcal{C}$ hanges to a single base in the coding region of mRNA can transform an amino acid codon into a stop codon, leading to the premature termination of translation. Termed nonsense mutations, premature termination codons (PTC) result in the formation of defective, truncated proteins. Genes are inactivated by nonsense mutations in approximately $11 \%$ of patients across several thousand rare genetic diseases. Additionally, they also cause tumor suppressor gene inactivation in about $10 \%$ of cancer patients. ${ }^{1-3}$

Traditionally used as Gram-negative antibacterial agents, the aminoglycoside class of compounds (Figure 1) have also been shown to bind and alter the conformation of eukaryotic ribosomes. This conformational change in the ribosomal A site allows for the pairing of a near-cognate aminoacyl-tRNA at a PTC site, inducing readthrough of the codon, and suppressing premature translation termination. Incorporation of an amino acid at the PTC can result in the expression of the wild type or alternative mutant allele and lead to the production of functional or near-functional proteins. ${ }^{4-6}$ Harnessing this mechanism of action has provided an approach to treat genetic disorders caused by nonsense mutations. ${ }^{7-10}$

The aminoglycoside class of antibiotics consist of pyranose, and less commonly furanose, units bound to a central 2deoxystreptamine (2-DOS) core. The carbohydrate bound at position 4 of 2-DOS is ring I, and the carbohydrate bound either at position 5 or at position 6 of 2-DOS is ring III (rings labeled in blue, Figure 1). The most clinically useful aminoglycoside antibiotics are typically disubstituted on the 4,5- or 4,6-hydroxy positions of 2-DOS. ${ }^{11}$ Natural features commonly include further glycosidic elongation $(3 \mathbf{a}-\mathbf{b}$, Figure
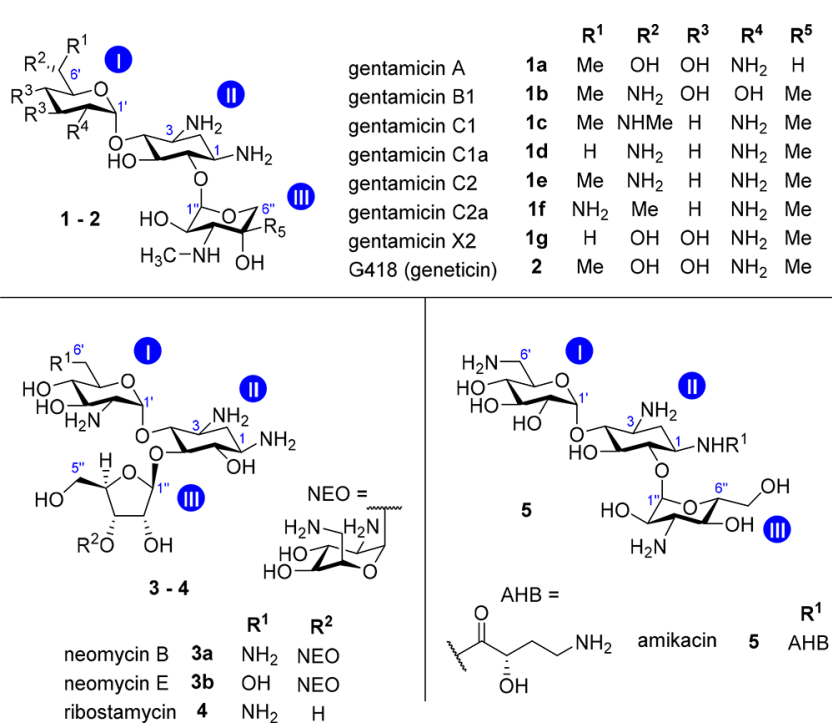

Figure 1. Examples of natural aminoglycosides.

Received: June 24, 2021

Accepted: August 4, 2021

Published: August 9, 2021 
$1)$ and $(S)$-4-amino-2-hydroxybutanoyl (AHB) substitution at the 2-DOS core $N$-terminals (5, Figure 1 ).

Aminoglycosides are typically produced as complex mixtures by fermentation of Gram-positive bacteria, and the challenges associated with isolating pure components from these mixtures have further complicated their study. ${ }^{12}$ For example, gentamicin is composed of gentamicins $\mathrm{C} 1, \mathrm{C} 1 \mathrm{a}, \mathrm{C} 2$, and $\mathrm{C} 2 \mathrm{a}(1$, Figure 1) in addition to various minor components including sisomicin, gentamicins A, B, B1, X2, 2-DOS, garamine, and garosamine. ${ }^{13-15}$ Therefore, access to pure synthetic analogs aids in the development of novel aminoglycosides with favorable therapeutic profiles.

Another significant challenge with the development of aminoglycosides as PTC readthrough agents centers around their clinical toxicity profile. Aminoglycosides, in general, exhibit nephrotoxic and ototoxic properties. ${ }^{16}$ Nephrotoxicity is often observed early during treatment, while irreversible ototoxicity incidence increases upon prolonged dosing. ${ }^{17}$ The mechanism of toxicity is attributed to perturbations in various intracellular process, all driven by accumulation and retention in the cochlear cells and proximal tubule cells, via mechanotransducer (MET) channels such as megalin and cubulin. ${ }^{18-20}$ Megalin and cubulin recognize and transport highly cationic molecules, including aminoglycosides. ${ }^{21-24}$

A strategy demonstrated by Ricci and colleagues to lower the ototoxicity of antibacterial agent sisomicin (6a Figure 2)

\begin{tabular}{|c|c|c|c|}
\hline & & $\mathrm{R}^{1}$ & $\mathbf{R}^{2}$ \\
\hline sisomicin & $6 \mathbf{a}$ & $\mathrm{H}$ & $\mathrm{H}$ \\
\hline $\mathrm{H}_{2} \longrightarrow 6^{\prime}$ & $6 b$ & $\mathrm{PhSO}_{2}$ & $\mathrm{H}$ \\
\hline & $6 c$ & Ms & $\mathrm{H}$ \\
\hline & $6 d$ & $\mathrm{Bz}$ & $\mathrm{H}$ \\
\hline $\mathrm{NH}_{2}$ & $6 e$ & $\mathrm{H}$ & $\mathrm{PhSO}_{2}$ \\
\hline (III) & $6 f$ & $\mathrm{H}$ & Ms \\
\hline & $6 g$ & $\mathrm{H}$ & $\mathrm{Bz}$ \\
\hline & $6 \mathrm{~h}$ & $\mathrm{PhSO}_{2}$ & $\mathrm{PhSO}_{2}$ \\
\hline $\mathrm{H}_{3} \mathrm{C}-\mathrm{N}_{1} \mathbf{1} 2 \mathrm{OH}$ & $6 i$ & Ms & Ms \\
\hline & 6j & Bz & Bz \\
\hline
\end{tabular}

Figure 2. Modification of sisomicin to reduce toxicity by Ricci. ${ }^{25}$

was to reduce the cationic charge of the molecule, which was achieved by eliminating basic sites from the sisomicin skeleton (Figure 2). ${ }^{25}$ Prior elucidation of the structure of bacterial ribosome-bound gentamicin C1a (1d, Figure 1) and paromomycin by X-ray crystallography suggested that the Ring II 1- and Ring III 3"-amino groups were nonessential sites for binding, therefore modification was not expected to affect therapeutic function. ${ }^{26}$ The introduction of amide and sulfonamide functionality was shown to reduce ototoxicity and decrease penetration of hair cell MET channels in rat cochlear cultures, thus providing a strategy to reduce the toxicity of aminoglycosides for PTC readthrough.

The Ricci et al. study was limited to sisomicin analogues. We recognized an opportunity to expand on this work by chemically synthesizing a library of known PTC readthrough agents with modified amino groups, hoping to reduce cell toxicity without compromising readthrough activity.

Examination of the published X-ray crystal structure of the G418 (2) aminoglycoside bound to the yeast $80 \mathrm{~S}$ ribosome suggested that replacement of the Ring I $2^{\prime}$-amino group may be a suitable starting point for these explorations (Figure 3). ${ }^{7,27}$ Notably, a direct relationship was previously reported between the basicity of the $2^{\prime}$-amino moiety and toxicity as
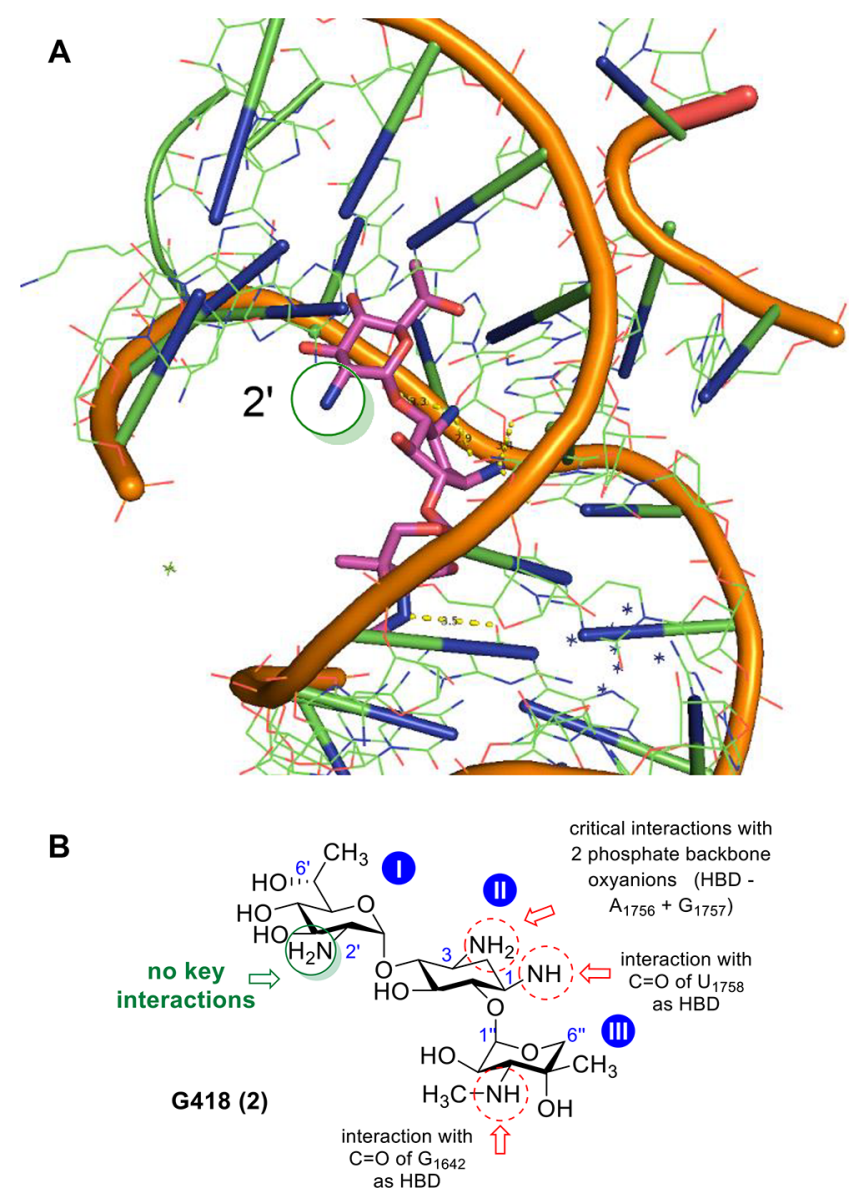

Figure 3. Graphical 3D representation (A) and 2D representation (B) of the key interaction of the four basic amine groups present in G418 (2) with the yeast $80 \mathrm{~S}$ ribosome. ${ }^{7,27}$ The $2^{\prime}$-amino group was identified as a potential basic moiety which could be substituted without detrimentally impacting PTC readthrough activity.

determined by $\mathrm{LD}_{50}$ values in mice. ${ }^{28}$ The work we present, herein, will document our efforts to reduce toxicity and maintain eukaryotic PTC readthrough activity of existing small molecules by modification of the aforementioned amino group.

After initially identifying the paromamine core as a scaffold, several generations of compounds have been reported by Baasov and colleagues as therapeutically relevant agents (Figure 4). ${ }^{29-35}$ Intrigued by the seminal work on designer

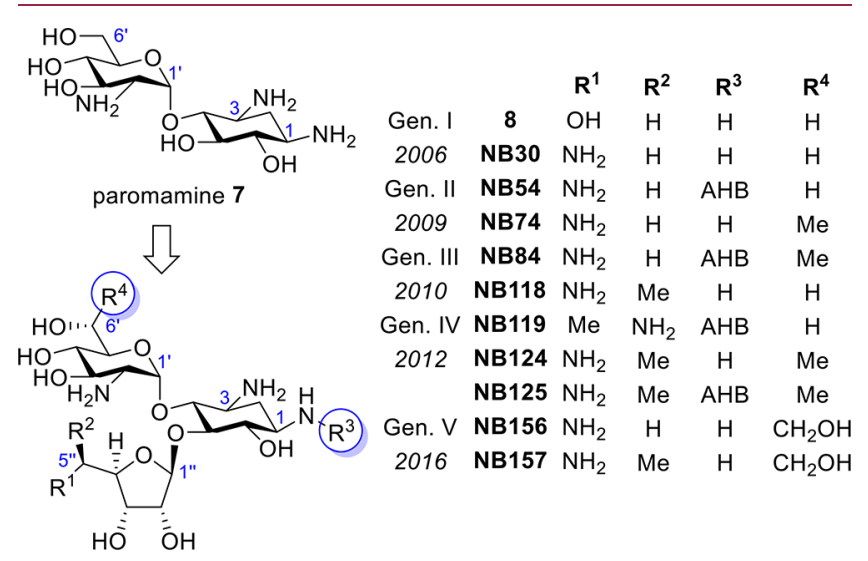

Figure 4. Evolution of synthetic aminoglycosides developed by Baasov and colleagues as eukaryotic PTC readthrough agents. 
aminoglycosides with improved PTC readthrough activity, we decided to apply our structural modification onto the core of NB124 (ELX-02), an aminoglycoside derivative in phase II clinical trials for treatment of cystic fibrosis and nephropathic cystinosis. $^{36}$

This led to the design of compound $9 a$, where the 2 '-amino group was replaced with a hydroxyl moiety (Figure 5). In

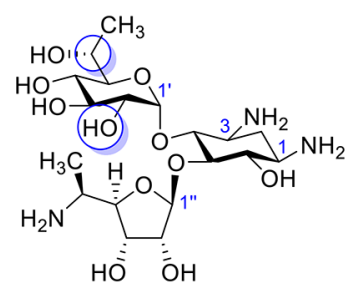

9a

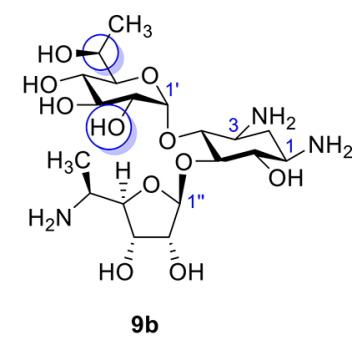

$9 b$
Figure 5. First-generation modified NB124 analogues with $2^{\prime}$ hydroxyl modifications.

addition to compound $(R)-9 \mathrm{a}$, we were able to prepare the diastereomeric $6^{\prime}$-alcohol, $(S)-9 \mathbf{b}$ (Figure 5). The impact of the stereoisomer at the $6^{\prime}$-position on PTC readthrough activity has not previously been explored, however others have noted the conformation of the $6^{\prime}$-alcohol impacts antibacterial activity. $^{37}$

To evaluate the PTC readthrough activity of the compounds we selected the lung carcinoma DMS-114 cell line with homozygous nonsense mutation R213X in the TP53 gene. This mutation was previously shown to be very responsive to PTC readthrough treatments. ${ }^{38}$ DMS-114 cells were exposed to the compounds at various concentrations over the course of 48 hours. Expression of the full-length p53, the PTC readthrough product, was determined. As anticipated, both G418 and NB124 induced concentration dependent increase in PTC readthrough (Figure 7a). NB124 was less active than G418 at lower concentrations but at $62 \mu \mathrm{g} / \mathrm{mL}$ they both elicited similar PTC readthrough. NB124 was not toxic to DMS-114 cells at concentrations up to $62 \mu \mathrm{g} / \mathrm{mL}$ but it showed significant toxicity at $125 \mu \mathrm{g} / \mathrm{mL}$ and higher concentrations. Replacement of the 2 -amine moiety with the alcohol led to a significant reduction in the PTC readthrough activity of compounds $\mathbf{9 a}$ and $\mathbf{9 b}$ compared to parent molecule NB124 (Figure 7a). We observed a concentration dependent increase in the production of full-length p53 with 9a starting at $125 \mu \mathrm{g} / \mathrm{mL}$. At $500 \mu \mathrm{g} / \mathrm{mL}$, this compound elicited PTC readthrough that reached $18 \%$ of the maximal PTC readthrough activity of the $62 \mu \mathrm{g} / \mathrm{mL}$ nontoxic dose of $\mathrm{NB124}$ (Figure 7a). Compound $\mathbf{9 b}$ did not show any PTC readthrough activity at concentrations up to $500 \mu \mathrm{g} / \mathrm{mL}$ indicating the importance of the stereoisomer at the $6^{\prime}$ position for PTC readthrough activity (Figure 7a). In addition to decreased PTC readthrough activity, we also observed a marked reduction in cytotoxicity of $9 a$ and $9 \mathbf{b}$ at concentrations up to $500 \mu \mathrm{g} / \mathrm{mL}$ compared to G418 or NB124. Despite the reduction in activity, a comparable toxicity versus efficacy value for compound $\mathbf{9 a}$, encouraged us to further explore the structure-activity relationship. Two approaches were considered to further understand and improve the structural aspects driving the PTC readthrough activity of these aminoglycoside derivatives.

The first was to understand whether the overall cationic charge of the molecule was important for driving cellular readthrough activity. Compounds $\mathbf{9 a}$ and $\mathbf{9 b}$ have three basic amine moieties and would possess an overall charge of +3 at physiological pH. In contrast, NB124 and G418 (2) contain four basic moieties and a +4 overall charge. If the cationic nature of the molecule as a whole was important for either cellular uptake or readthrough activity, then an analogue, such as compound 9c, may shed some light on the structural drivers of cellular readthrough in our DMS-114 system (Figure 6).
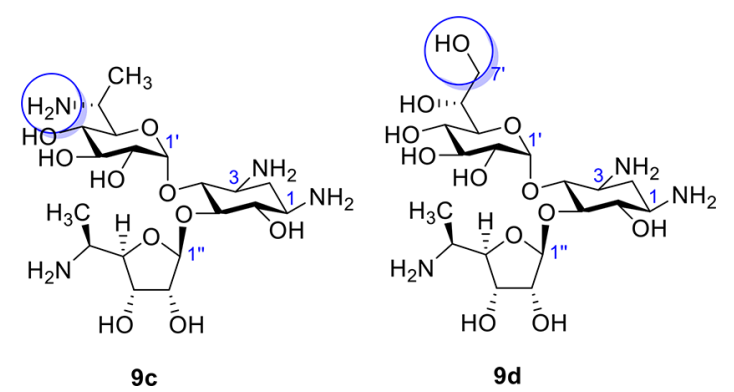

Figure 6. Second-generation modified NB124 analogues with $2^{\prime}$ hydroxyl moieties and $6^{\prime} / 7^{\prime}$ modifications.

The second approach relied on the observation initially reported by Simonson and colleagues that the introduction of a hydroxylmethyl group at the ring I $6^{\prime}, 7^{\prime}$-positions in paromamine did not affect binding to the bacterial ribosome relative to the alcohol. ${ }^{39}$ Subsequent incorporation of the $7^{\prime}$ hydroxyl group on NB124 by Baasov and co-workers, however, suggested improved activity via interactions with RNA bases in the eukaryotic ribosome structure (NB157). ${ }^{34}$

This led to the design of compound $9 \mathbf{d}$, which incorporated the additional primary alcohol at the $7^{\prime}$-position, while also maintaining the reduced cationic nature of compound 9a (Figure 6). We were interested in evaluating whether addition of a 7 '-hydroxyl group would be sufficient to improve the readthrough activity to levels similar to that of G418 (2) or NB124.

As such we sought to synthesize both $9 \mathrm{c}$ and $9 \mathrm{~d}$ to better understand the structural-activity relationship of charge, ring I substituents, and PTC readthrough activity.

Similarly to triamine analogue $9 \mathbf{b}$, the tetraamine analogue 9c did not display any PTC readthrough activity at concentrations up to $500 \mu \mathrm{g} / \mathrm{mL}$, suggesting that the overall cationic charge was not essential for readthrough. Most promisingly, however, was the significant concentration dependent increase in the PTC readthrough activity of the triamine analogue 9d. This compound induced p53 PTC readthrough starting at $31 \mu \mathrm{g} / \mathrm{mL}$ and at 125 and $250 \mu \mathrm{g} / \mathrm{mL}$ readthrough reached levels similar to those elicited by 15 and $31 \mu \mathrm{g} / \mathrm{mL}$ NB124, respectively (Figure $7 \mathrm{~b}$ ). Consistent with our goal, 9d did not show cell toxicity at concentrations up to $500 \mu \mathrm{g} / \mathrm{mL}$.

To gain a better understanding of the safety of these novel compounds, we measured their effect on human fibroblasts viability and compared them to that of G418 and NB124 (Figure 8). Both novel compounds 9a and 9d did not significantly inhibit cell viability at concentrations up to 0.5 $\mathrm{mg} / \mathrm{mL}$, however compound $9 \mathrm{~d}$ caused a $15 \%$ reduction in cell viability at $1 \mathrm{mg} / \mathrm{mL}$. Both $\mathbf{G 4 1 8}$ and NB124 caused significant concentration dependent reduction in cell viability with $1 \mathrm{mg} / \mathrm{mL}$ eliciting $72 \%$ and $50 \%$ reduction, respectively (Figure 8). 
A

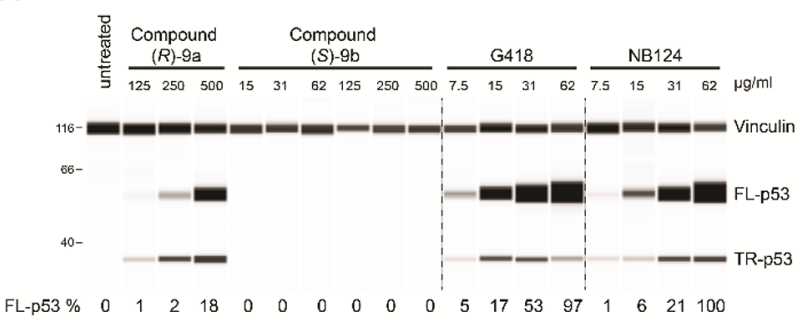

B

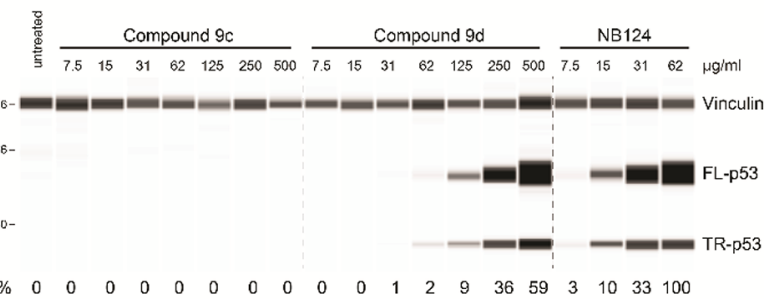

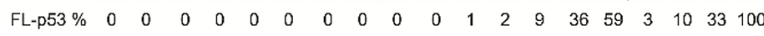

Figure 7. Effect of compounds $\mathbf{9 a}-\mathbf{b}(\mathrm{A})$ and $\mathbf{9 c}-\mathbf{d}$ (B) on TP53 PCT readthrough. DMS-114 were exposed to various concentrations of indicated compounds for $48 \mathrm{~h}$, and p53 levels (full-length, FL-p53; truncated, TR-p53) were determined using capillary electrophoresis western analysis. Vinculin was used as loading control. The numbers under the lanes indicate the percent amounts of FL-p53 normalized against vinculin, relative to that of $\mathrm{NB124}$ at $62 \mu \mathrm{g} / \mathrm{mL}$.

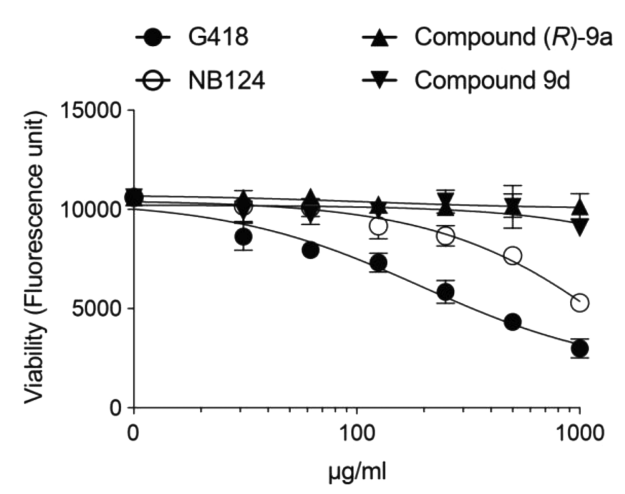

Figure 8. Fibroblast toxicity studies on 9a and 9d. Wild-type fibroblasts were exposed to various concentrations of indicated compounds for $48 \mathrm{~h}$ and cell viability was measured using the Promega ApoLive-Glo Multiplex Assay kit.

The synthesis of compounds $\mathbf{9 a}-\mathbf{d}$ was achieved by coupling ring I to ring II via chemical glycosylation (Scheme 1). The intermediate was subsequently coupled to ring III to give the desired aminoglycoside skeleton. Cleavage of the protecting

Scheme 1. Generalized Synthetic Strategy Towards Aminoglycosides 9a-d

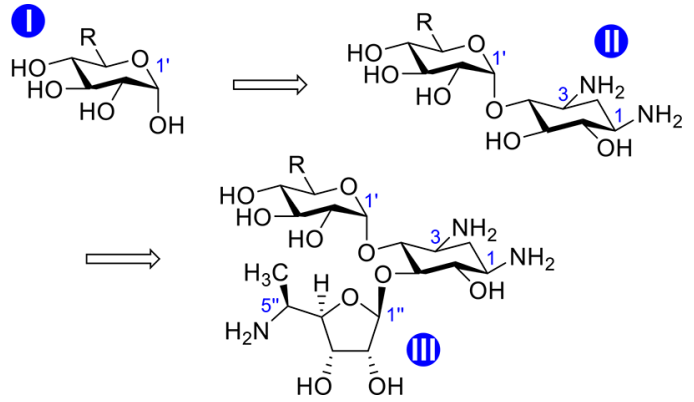

groups and conversion to the corresponding sulfate salts yielded the final products for biological evaluation.

The ring I analogues of compounds $9 a$ and $9 \mathbf{b}$ were prepared in an almost-identical fashion (Scheme 2). Thioglycosides $10 \mathbf{a}-\mathbf{b}$ were oxidized at the $6^{\prime}$-positions to afford aldehydes $\mathbf{1 1 a}-\mathbf{b} .^{40,41}$ Treatment with methylmagnesium bromide gave alcohols $\mathbf{1 2} \mathbf{a}-\mathbf{b}$ as diastereomeric mixtures. Benzoylation afforded diastereomerically pure glycosyl donors 13a-b after chromatographic separation, in preparation for coupling to ring II.

Scheme $2^{a}$
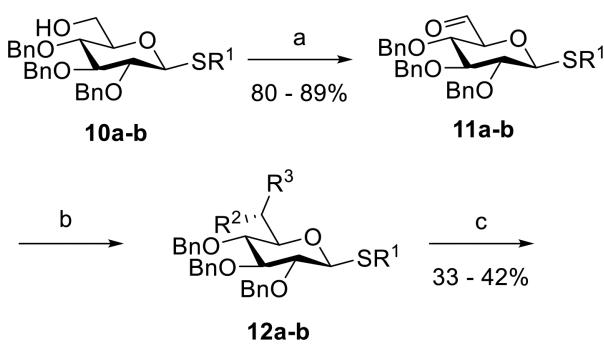

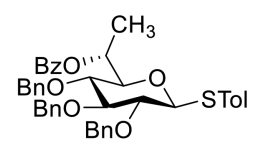

$13 a$

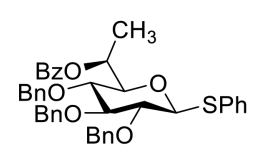

13b a 10-12a: $\mathrm{R}^{1}=$ Tol, $\mathrm{R}^{2}=\mathrm{OH}, \mathrm{R}^{3}=$ Me. 10-12b: $\mathrm{R}^{1}=\mathrm{Ph}, \mathrm{R}^{2}=\mathrm{Me}$ $\mathrm{R}^{3}=\mathrm{OH}$. Route towards 13a-b: (a) DMP, $\mathrm{CH}_{2} \mathrm{Cl}_{2}$; (b) $\mathrm{MeMgBr}$, THF; (c) BzCl, pyridine.

The ring I synthesis of analogue 9c began with known azide 14, accessed stereoselectively from L-ascorbic acid (Scheme 3). ${ }^{42}$ Global acyl protection enabled the $\beta$-thioglycoside 15 to

Scheme $3^{a}$

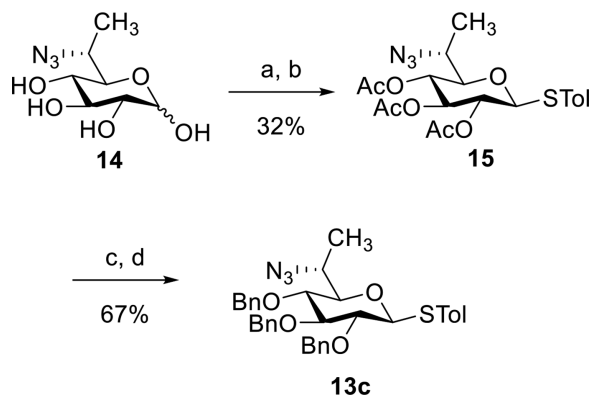

${ }^{a}$ Route towards 13c: (a) $\mathrm{Ac}_{2} \mathrm{O}, \mathrm{NaOAc}$; (b) TolSH, $\mathrm{BF}_{3} \cdot \mathrm{OEt}_{2}$, $\mathrm{CH}_{2} \mathrm{Cl}_{2}$; (c) $\mathrm{NaOMe}, \mathrm{MeOH}$ then Amberlyte $15\left(\mathrm{H}^{+}\right)$; (d) $\mathrm{BnBr}$, $\mathrm{NaH}, \mathrm{DMF}$.

subsequently be accessed selectively over two steps. Further protecting group manipulations afforded ring I (13c) ready for coupling to ring II.

The synthesis of analogue $9 \mathbf{d}$ began from the tetrabenzylated glucose species 16 (Scheme 4$).{ }^{43}$ Oxidation of 16 under Swern conditions followed by Wittig methylenation elongated the ring I framework to give 17. The resulting vinyl group underwent Upjohn dihydroxylation to give the corresponding glycol as a diastereomeric mixture. Following stannylene acetal-mediated selective protection of the primary $7^{\prime}$-alcohol, the desired stereoisomer $\mathbf{1 8}$ was isolated after chromatographic separation. $^{44} \mathrm{X}$-ray crystallography confirmed the stereo- 
Scheme $4^{a}$

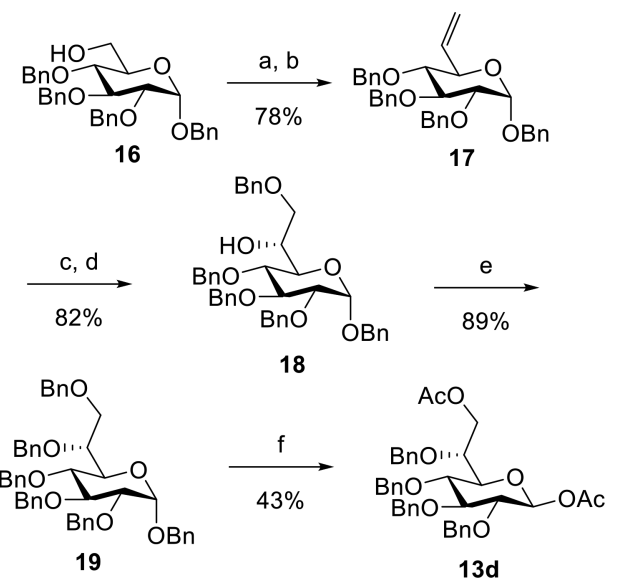

${ }^{a}$ Route towards 13d: (a) $(\mathrm{COCl})_{2}, \mathrm{DMSO} \mathrm{NEt}_{3}, \mathrm{CH}_{2} \mathrm{Cl}_{2}$; (b) $\mathrm{MePPh}_{3} \mathrm{Br}$, NaHMDS, THF; (c) $\mathrm{OsO}_{4}, \mathrm{NMO}, t \mathrm{BuOH} /$ acetone/ $\mathrm{H}_{2} \mathrm{O}$; (d) $\mathrm{Bu}_{2} \mathrm{SnO}, \mathrm{MeOH}$ then $\mathrm{BnBr}$, $\mathrm{TBABr}$, toluene; (e) $\mathrm{BnBr}$, $\mathrm{NaH}, \mathrm{DMF}$; (f) $\mathrm{Ac}_{2} \mathrm{O}, \mathrm{H}_{2} \mathrm{SO}_{4}, \mathrm{AcOH}$.

chemistry of $\mathbf{1 8}$. Benzyl protection of $\mathbf{1 8}$ gave fully benzylated species 19. Treatment with acetic anhydride in the presence of sulfuric acid displaced the 1 ' - and 7 '-benzyl groups selectively to afford diacetate $13 \mathrm{~d}$ as the glycosyl donor. ${ }^{43}$

Thioglycosides $13 \mathbf{a}-\mathbf{c}$ were treated with NIS in the presence of triflic acid and underwent glycosylation reactions with alcohol 23, which was accessed enzymatically (Scheme 5). ${ }^{35,45}$ Acetate $\mathbf{1 3 d}$ was reacted with $\mathbf{2 3}$ in the presence of triflic acid. Global acetate cleavage of $20 a-d$, followed by regioselective reacylation, afforded alcohols $\mathbf{2 1 a} \mathbf{- b}$ as glycosyl acceptors. ${ }^{46,47}$ A glycosylation reaction with known glycosyl donor trichloroacetimidate ring III $(\mathbf{2 4})^{32,48}$ was carried out under standard Lewis acidic conditions to give the final protected aminoglycosides $(22 a-d)$. Cleavage of the protecting groups, followed by treatment with sulfuric acid, gave the corresponding sulfate salts $\mathbf{9 a}-\mathbf{d}$ for biological evaluation.

We have prepared a series of structural variants of NB124 and NB157, which have illuminated the role of the amino- and hydroxyl-groups at the $6^{\prime}$ - and $2^{\prime}$-position of ring I. The goal of these synthetic efforts was to reduce the overall cationic charge of the parent molecules in an attempt to widen the therapeutic window for readthrough activity over dose-limiting nephrotoxicity and ototoxicity. PTC readthrough agents exhibit the potential to treat a wide range of severe genetic diseases, however the safety profile of aminoglycoside readthrough agents will need to be improved upon to maximize the therapeutic potential. Highly cationic charged aminoglycosides are taken up into proximal tubule and cochlear cells via transporters such as megalin, which recognize cationic molecules. Reductions in the overall cationic nature of the aminoglycosides may serve to reduce overall toxicity but must not come at the expense of readthrough activity. Our efforts to identify potent aminoglycoside agents with reduced overall cationic charge resulted in the identification of compound 9d as a promising analogue. Further evaluation of the in vivo properties and readthrough activity of compound $\mathbf{9 d}$, together with assessment of the toxicity profile remains ongoing.
Scheme $5^{a}$
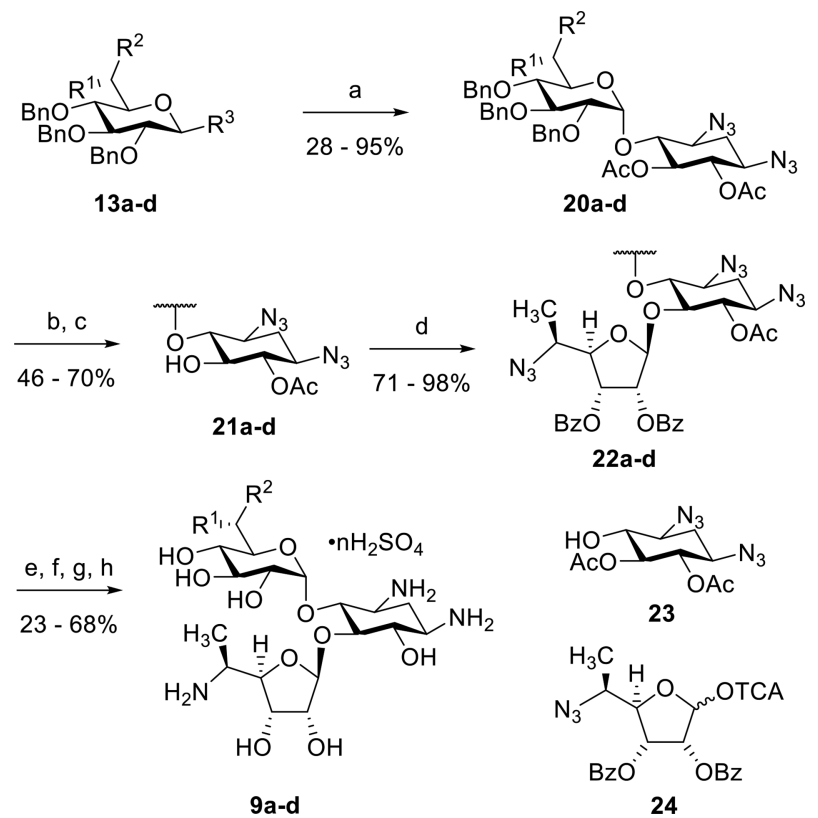

24

${ }^{a}$ 13/20-22a: $\mathrm{R}^{1}=\mathrm{OBz}, \mathrm{R}^{2}=\mathrm{Me}, \mathrm{R}^{3}=\mathrm{STol}$. 13/20-22b: $\mathrm{R}^{1}=\mathrm{Me}$, $\mathrm{R}^{2}=\mathrm{OBz}, \mathrm{R}^{3}=\mathrm{SPh}$. 13/20-22c: $\mathrm{R}^{1}=\mathrm{N}_{3}, \mathrm{R}^{2}=\mathrm{Me}, \mathrm{R}^{3}=$ STol. 13/ 20-22d: $\mathrm{R}^{1}=\mathrm{OBn}, \mathrm{R}^{2}=\mathrm{CH}_{2} \mathrm{OAc}, \mathrm{R}^{3}=\mathrm{OAc}$. 9a: $\mathrm{R}^{1}=\mathrm{OH}, \mathrm{R}^{2}=\mathrm{Me}$. 9b: $\mathrm{R}^{1}=\mathrm{Me}, \mathrm{R}^{2}=\mathrm{OH} .9 \mathrm{c}: \mathrm{R}^{1}=\mathrm{NH}_{2}, \mathrm{R}^{2}=$ Me. 9d: $\mathrm{R}^{1}=\mathrm{OH}, \mathrm{R}^{2}=$ $\mathrm{CH}_{2} \mathrm{OH}$. Route towards $9 \mathbf{a}-\mathbf{d}$ : (a) 23; for $\mathbf{1 3 a}-\mathbf{c}$ plus NIS, TfOH, $\mathrm{CH}_{2} \mathrm{Cl}_{2} / \mathrm{Et}_{2} \mathrm{O}$; for 13d plus TMSOTf, $4 \AA$ mol. sieves, $\mathrm{CH}_{2} \mathrm{Cl}_{2} / \mathrm{Et}_{2} \mathrm{O}$; (b) $\mathrm{NaOMe}, \mathrm{THF} / \mathrm{MeOH}$; (c) $\mathrm{Ac}_{2} \mathrm{O}$, pyridine; (d) 24, $\mathrm{BF}_{3} \cdot \mathrm{OEt}_{2}, 4$ $\AA$ mol. sieves, $\mathrm{CH}_{2} \mathrm{Cl}_{2}$; (e) NaOMe, MeOH; (f) not applied to 22ab; for 22c-d $\mathrm{PMe}_{3}, \mathrm{NaOH}, \mathrm{THF} /$ water; $(\mathrm{g})$ for 22a-b hydrazine monohydrate, $\mathrm{Pd} / \mathrm{C}, \mathrm{MeOH}$; for $\mathbf{2 2 c}-\mathbf{d ~ H}_{2}, \mathrm{Pd} / \mathrm{C}, \mathrm{AcOH} / \mathrm{H}_{2} \mathrm{O}$; (h) $\mathrm{H}_{2} \mathrm{SO}_{4}$ (aq.). TCA = trichloroacetimidate.

\section{ASSOCIATED CONTENT}

Supporting Information

The Supporting Information is available free of charge at https://pubs.acs.org/doi/10.1021/acsmedchemlett.1c00349.

Experimental procedures toward the synthesis of compounds $9 \mathbf{a}-\mathbf{d}$ and associated characterization data, a description of the biological evaluation procedures, and X-ray crystallography data (PDF)

\section{AUTHOR INFORMATION}

\section{Corresponding Authors}

Michel Roberge - Department of Biochemistry and Molecular Biology, University of British Columbia, Vancouver, British Columbia V6T 1Z3, Canada; Email: michelr@mail.ubc.ca

David A. Powell - Inception Sciences Canada, Vancouver, British Columbia V5T 4T5, Canada; Present Address: Chinook Therapeutics, Inc., Vancouver, BC; ○ orcid.org/0000-0002-8710-7390; Email: dpowell@ chinooktx.com

\section{Authors}

Michael Popadynec - Ferrier Research Institute, Victoria University of Wellington, Wellington 6012, New Zealand

Alireza Baradaran-Heravi - Department of Biochemistry and Molecular Biology, University of British Columbia, Vancouver, British Columbia V6T 1Z3, Canada

Benjamin Alford - Ferrier Research Institute, Victoria University of Wellington, Wellington 6012, New Zealand 
Scott A. Cameron - Ferrier Research Institute, Victoria University of Wellington, Wellington 6012, New Zealand; (1) orcid.org/0000-0003-2669-8622

Keith Clinch - Ferrier Research Institute, Victoria University of Wellington, Wellington 6012, New Zealand

Jennifer M. Mason - Ferrier Research Institute, Victoria University of Wellington, Wellington 6012, New Zealand

Phillip M. Rendle - Ferrier Research Institute, Victoria University of Wellington, Wellington 6012, New Zealand

Olga V. Zubkova - Ferrier Research Institute, Victoria University of Wellington, Wellington 6012, New Zealand; (1) orcid.org/0000-0002-6892-8812

Zhonghong Gan - Sussex Research Laboratories, Inc., Ottawa, Ontario K1A 0R6, Canada

Hui Liu - Sussex Research Laboratories, Inc., Ottawa, Ontario K1A 0R6, Canada

Oscar Rebollo - Sussex Research Laboratories, Inc., Ottawa, Ontario K1A 0R6, Canada

Dennis M. Whitfield - Sussex Research Laboratories, Inc., Ottawa, Ontario K1A 0R6, Canada

Fengyang Yan - Sussex Research Laboratories, Inc., Ottawa, Ontario K1A 0R6, Canada

Complete contact information is available at:

https://pubs.acs.org/10.1021/acsmedchemlett.1c00349

\section{Author Contributions}

D.A.P., A.B.H., and M.R. conceived and designed all compounds for biological evaluation. The syntheses of all compounds were designed, performed and characterized by B.A., K.C., Z.G., J.M.M., O.R., D.M.W., F.Y., H.L., O.V.Z., and P.M.R. D.A.P., A.B.H., and M.R. designed and performed biological evaluations of final compounds. S.A.C. obtained Xray crystallography data. M.P. wrote the manuscript with contributions from D.A.P., A.B.H., and M.R. M.P. and A.B.H. compiled the Supporting Information. All authors have given approval to the final version of the manuscript.

\section{Funding}

Seed funding for this work was provided by Versant Ventures.

\section{Notes}

The authors declare the following competing financial interest(s): D.A.P. is a former employee of Inception Sciences Canada and is a current employee of Chinook Therapeutics, Inc., and owns stock and/or holds stock options in the Company.

\section{ABBREVIATIONS}

2-DOS, 2-deoxystreptamine; AHB, (S)-4-amino-2-hydroxybutanoyl; DMF, dimethylformamide; DMP, Dess-Martin periodinane; DMSO, dimethyl sulfoxide; $\mathrm{EC}_{50}$, effective concentration, 50\%; $\mathrm{LC}_{50}$, lethal concentration, 50\%; MET, mechanotransducer; NaHMDS, sodium hexamethyldisilazide; NIS, $N$-iodosuccinimide; NMD, nonsense-mediated mRNA decay; NMO, $N$-methylmorpholine $N$-oxide; OTCA, trichloroacetimidate; PTC, premature termination codon; TCA, trichloroacetonitrile; THF, tetrahydrofuran

\section{REFERENCES}

(1) Mort, M.; Ivanov, D.; Cooper, D. N.; Chuzhanova, N. A. A meta-analysis of nonsense mutations causing human genetic disease. Hum. Mutat. 2008, 29, 1037-1047.

(2) Du, M.; Jones, J. R.; Lanier, J.; Keeling, K. M.; Lindsey, R. J.; Tousson, A.; Bebök, Z.; Whitsett, J. A.; Dey, C. R.; Colledge, W. H.;
Evans, M. J.; Sorscher, E. J.; Bedwell, D. M. Aminoglycoside suppression of a premature stop mutation in a Cftr-/- mouse carrying a human CFTR-G542X transgene. J. Mol. Med. 2002, 80, 595-604.

(3) Bidou, L.; Hatin, I.; Perez, N.; Allamand, V.; Panthier, J. J.; Rousset, J. P. Premature stop codons involved in muscular dystrophies show a broad spectrum of readthrough efficiencies in response to gentamicin treatment. Gene Ther. 2004, 11, 619-627.

(4) Nagel-Wolfrum, K.; Möller, F.; Penner, I.; Baasov, T.; Wolfrum, $\mathrm{U}$. Targeting nonsense mutations in diseases with translational readthrough-inducing drugs (TRIDs). BioDrugs 2016, 30, 49-74.

(5) Scoto, M.; Finkel, R.; Mercuri, E.; Muntoni, F. Genetic therapies for inherited neuromuscular disorders. Lancet Child Adolesc. Health 2018, 2, 600-609.

(6) Keeling, K.; Bedwell, D. Pharmacological suppression of premature stop mutations that cause genetic diseases. Curr. Pharmacogenomics 2005, 3, 259-269.

(7) Garreau de Loubresse, N.; Prokhorova, I.; Holtkamp, W.; Rodnina, M. V.; Yusupova, G.; Yusupov, M. Structural basis for the inhibition of the eukaryotic ribosome. Nature 2014, 513, 517-522.

(8) Rabea, S. M.; Baradaran-Heravi, A.; Balgi, A. D.; Krause, A.; Hosseini Farahabadi, S.; Roberge, M.; Grierson, D. S. 2-Aminothiazole-4-carboxamides enhance readthrough of premature termination codons by aminoglycosides. ACS Med. Chem. Lett. 2019, 10, $726-731$

(9) Manuvakhova, M.; Keeling, K. I. M.; Bedwell, D. M. Aminoglycoside antibiotics mediate context-dependent suppression of termination codons in a mammalian translation system. RNA 2000, 6, 1044-1055.

(10) Clancy, J. P.; Bebök, Z.; Ruiz, F.; King, C.; Jones, J.; Walker, L.; Greer, H.; Hong, J.; Wing, L.; Macaluso, M.; Lyrene, R.; Sorscher, E. J.; Bedwell, D. M. Evidence that systemic gentamicin suppresses premature stop mutations in patients with cystic fibrosis. Am. J. Respir. Crit. Care Med. 2001, 163, 1683-1692.

(11) Hainrichson, M.; Nudelman, I.; Baasov, T. Designer aminoglycosides: the race to develop improved antibiotics and compounds for the treatment of human genetic diseases. Org. Biomol. Chem. 2008, $6,227-239$.

(12) Mingeot-Leclercq, M.-P.; Glupczynski, Y.; Tulkens, P. M. Aminoglycosides: activity and resistance. Antimicrob. Agents Chemother. 1999, 43, 727-737.

(13) Vydrin, A. F.; Shikhaleev, I. V.; Makhortov, V. L.; Shcherenko, N. N.; Kolchanova, N. V. Component composition of gentamicin sulfate preparations. Pharm. Chem. J. 2003, 37, 448-450.

(14) Friesen, W. J.; Johnson, B.; Sierra, J.; Zhuo, J.; Vazirani, P.; Xue, X.; Tomizawa, Y.; Baiazitov, R.; Morrill, C.; Ren, H.; Babu, S.; Moon, Y.-C.; Branstrom, A.; Mollin, A.; Hedrick, J.; Sheedy, J.; Elfring, G.; Weetall, M.; Colacino, J. M.; Welch, E. M.; Peltz, S. W. The minor gentamicin complex component, $\mathrm{X} 2$, is a potent premature stop codon readthrough molecule with therapeutic potential. PLoS One 2018, 13, No. e0206158.

(15) Rajasekaran, P.; Crich, D. Synthesis of gentamicin minor components: gentamicin B1 and gentamicin X2. Org. Lett. 2020, 22, $3850-3854$.

(16) Mingeot-Leclercq, M.-P.; Tulkens, P. M. Aminoglycosides: nephrotoxicity. Antimicrob. Agents Chemother. 1999, 43, 1003-1012.

(17) Xie, J.; Talaska, A. E.; Schacht, J. New developments in aminoglycoside therapy and ototoxicity. Hear. Res. 2011, 281, 28-37.

(18) Quiros, Y.; Vicente-Vicente, L.; Morales, A. I.; Lopez-Novoa, J. M.; Lopez-Hernandez, F. J. An integrative overview on the mechanisms underlying the renal tubular cytotoxicity of gentamicin. Toxicol. Sci. 2011, 119, 245-256.

(19) Tauris, J.; Christensen, E. I.; Nykjær, A.; Jacobsen, C.; Petersen, C. M.; Ovesen, T. Cubilin and megalin co-localize in the neonatal inner ear. Audiol. Neuro-Otol. 2009, 14, 267-278.

(20) Hosokawa, S.; Hosokawa, K.; Ishiyama, G.; Ishiyama, A.; Lopez, I. A. Immunohistochemical localization of megalin and cubilin in the human inner ear. Brain Res. 2018, 1701, 153-160. 
(21) Nagai, J.; Takano, M. Molecular aspects of renal handling of aminoglycosides and strategies for preventing the nephrotoxicity. Drug Metab. Pharmacokinet. 2004, 19, 159-170.

(22) Nagai, J.; Tanaka, H.; Nakanishi, N.; Murakami, T.; Takano, M. Role of megalin in renal handling of aminoglycosides. Am. J. Physiol. Renal Physiol. 2001, 281, F337-F344.

(23) Dagil, R.; O'Shea, C.; Nykjær, A.; Bonvin, A. M. J. J.; Kragelund, B. B. Gentamicin binds to the megalin receptor as a competitive inhibitor using the common ligand binding motif of complement type repeats. J. Biol. Chem. 2013, 288, 4424-4435.

(24) Nagai, J.; Takano, M. Entry of aminoglycosides into renal tubular epithelial cells via endocytosis-dependent and endocytosisindependent pathways. Biochem. Pharmacol. 2014, 90, 331-337.

(25) Huth, M. E.; Han, K.-H.; Sotoudeh, K.; Hsieh, Y.-J.; Effertz, T.; Vu, A. A.; Verhoeven, S.; Hsieh, M. H.; Greenhouse, R.; Cheng, A. G.; Ricci, A. J. Designer aminoglycosides prevent cochlear hair cell loss and hearing loss. J. Clin. Invest. 2015, 125, 583-592.

(26) Yoshizawa, S. Structural origins of gentamicin antibiotic action. EMBO Journal 1998, 17, 6437-6448.

(27) Figure created with OpenSource PyMOL, version 2.1.0, using G418 structure (PDB 5NDG).

(28) Chen, L.; Hainrichson, M.; Bourdetsky, D.; Mor, A.; Yaron, S.; Baasov, T. Structure-toxicity relationship of aminoglycosides: correlation of $2^{\prime}$-amine basicity with acute toxicity in pseudodisaccharide scaffolds. Bioorg. Med. Chem. 2008, 16, 8940-8951.

(29) Palmer, E.; Wilhelm, J. M. Mistranslation in a eucaryotic organism. Cell 1978, 13, 329-334.

(30) Nudelman, I.; Rebibo-Sabbah, A.; Shallom-Shezifi, D.; Hainrichson, M.; Stahl, I.; Ben-Yosef, T.; Baasov, T. Redesign of aminoglycosides for treatment of human genetic diseases caused by premature stop mutations. Bioorg. Med. Chem. Lett. 2006, 16, 63106315.

(31) Nudelman, I.; Rebibo-Sabbah, A.; Cherniavsky, M.; Belakhov, V.; Hainrichson, M.; Chen, F.; Schacht, J.; Pilch, D. S.; Ben-Yosef, T.; Baasov, T. Development of novel aminoglycoside (NB54) with reduced toxicity and enhanced suppression of disease-causing premature stop mutations. J. Med. Chem. 2009, 52, 2836-2845.

(32) Nudelman, I.; Glikin, D.; Smolkin, B.; Hainrichson, M.; Belakhov, V.; Baasov, T. Repairing faulty genes by aminoglycosides: development of new derivatives of Geneticin (G418) with enhanced suppression of diseases-causing nonsense mutations. Bioorg. Med. Chem. 2010, 18, 3735-3746.

(33) Kandasamy, J.; Atia-Glikin, D.; Shulman, E.; Shapira, K.; Shavit, M.; Belakhov, V.; Baasov, T. Increased selectivity toward cytoplasmic versus mitochondrial ribosome confers improved efficiency of synthetic aminoglycosides in fixing damaged genes: a strategy for treatment of genetic diseases caused by nonsense mutations. J. Med. Chem. 2012, 55, 10630-10643.

(34) Sabbavarapu, N. M.; Shavit, M.; Degani, Y.; Smolkin, B.; Belakhov, V.; Baasov, T. Design of novel aminoglycoside derivatives with enhanced suppression of diseases-causing nonsense mutations. ACS Med. Chem. Lett. 2016, 7, 418-423.

(35) Greenberg, W. A.; Priestley, E. S.; Sears, P. S.; Alper, P. B.; Rosenbohm, C.; Hendrix, M.; Hung, S.-C.; Wong, C.-H. Design and synthesis of new aminoglycoside antibiotics containing neamine as an optimal core structure: correlation of antibiotic activity with in vitro inhibition of translation. J. Am. Chem. Soc. 1999, 121, 6527-6541.

(36) Brasell, E. J.; Chu, L. L.; Akpa, M. M.; Eshkar-Oren, I.; Alroy, I.; Corsini, R.; Gilfix, B. M.; Yamanaka, Y.; Huertas, P.; Goodyer, P. The novel aminoglycoside, ELX-02, permits CTNS ${ }^{W 138 X}$ translational readthrough and restores lysosomal cystine efflux in cystinosis. PLoS One 2019, 14, No. e0223954.

(37) Mandhapati, A. R.; Yang, G.; Kato, T.; Shcherbakov, D.; Hobbie, S. N.; Vasella, A.; Böttger, E. C.; Crich, D. Structure-based design and synthesis of apramycin-paromomycin analogues. Importance of the configuration at the $6^{\prime}$-position and differences between the $6^{\prime}$-amino and hydroxy series. J. Am. Chem. Soc. 2017, 139, 1461114619.
(38) Floquet, C.; Deforges, J.; Rousset, J.-P.; Bidou, L. Rescue of non-sense mutated p53 tumor suppressor gene by aminoglycosides. Nucleic Acids Res. 2011, 39, 3350-3362.

(39) Simonsen, K. B.; Ayida, B. K.; Vourloumis, D.; Takahashi, M.; Winters, G. C.; Barluenga, S.; Qamar, S.; Shandrick, S.; Zhao, Q.; Hermann, T. Novel paromamine derivatives exploring shallow-groove recognition of ribosomal-decoding-site RNA. ChemBioChem 2002, 3, 1223.

(40) Pfäffli, P. J.; Hixson, S. H.; Anderson, L. Thioglycosides having $O$-benzyl blocking groups as intermediates for the systematic, sequential synthesis of oligosaccharides. Synthesis of isomaltose. Carbohydr. Res. 1972, 23, 195-206.

(41) France, R. R.; Compton, R. G.; Davis, B. G.; Fairbanks, A. J.; Rees, N. V.; Wadhawan, J. D. Selective electrochemical glycosylation by reactivity tuning. Org. Biomol. Chem. 2004, 2, 2195-2202.

(42) Blériot, Y.; Masaguer, C. F.; Charlwood, J.; Winchester, B. G.; Lane, A. L.; Crook, S.; Watkin, D. J.; Fleet, G. W. J. 6R-, and 6S, -6CMethylglucose from D-glucuronolactone: Efficient synthesis of a seven carbon fucose analogue: Inhibition of some enzymes of primary metabolism. Tetrahedron 1997, 53, 15135-15146.

(43) Paulsen, H.; Paal, M. Synthese der T-antigenen trisaccharide $O$ $\beta$-D-galactopyranosyl- $(1 \rightarrow 3)$-O- $(2$-acetamido-2-desoxy- $\alpha$-D-galactopyranosyl)-( $1 \rightarrow 6)$-D-galactopyranose und $O$ - $\beta$-D-galactopyranosyl$(1 \rightarrow 3)-O$-(2-acetamido-2-desoxy- $\alpha$-D-galactopyranosyl)-( $1 \rightarrow 6)$-Dglucopyranose und deren anknüpfung an proteine. Carbohydr. Res. 1983, 113, 203-218.

(44) Dong, L.; Roosenberg, J. M.; Miller, M. J. Total synthesis of desferrisalmycin B. J. Am. Chem. Soc. 2002, 124, 15001-15005.

(45) Vourloumis, D.; Takahashi, M.; Winters, G. C.; Simonsen, K. B.; Ayida, B. K.; Barluenga, S.; Qamar, S.; Shandrick, S.; Zhao, Q.; Hermann, T. Novel 2,5-dideoxystreptamine derivatives targeting the ribosomal decoding site RNA. Bioorg. Med. Chem. Lett. 2002, 12, $3367-3372$.

(46) Li, J.; Chen, H.-N.; Chang, H.; Wang, J.; Chang, C.-W. T. Tuning the regioselectivity of the Staudinger reaction for the facile synthesis of kanamycin and neomycin class antibiotics with $\mathrm{N}-1$ modification. Org. Lett. 2005, 7, 3061-3064.

(47) Ding, Y.; Swayze, E. E.; Hofstadler, S. A.; Griffey, R. H. Efficient synthesis of neomycin B related aminoglycosides. Tetrahedron Lett. 2000, 41, 4049-4052.

(48) Kandasamy, J.; Atia-Glikin, D.; Belakhov, V.; Baasov, T. Repairing faulty genes by aminoglycosides: Identification of new pharmacophore with enhanced suppression of disease-causing nonsense mutations. MedChemComm 2011, 2, 165-17. 